\title{
Scarcity-weighted global land and metal footprints
}

\section{David Font Vivanco ${ }^{1,2^{*}}$, Benjamin $\underline{\text { Sprecher }}{ }^{2,3}$, and Edgar $\underline{\text { Hertwich }}{ }^{2}$}

\author{
${ }^{1}$ UCL Institute for Sustainable Resources, University College London, 14 Upper Woburn Place, WC1H \\ ONN London, United Kingdom \\ ${ }^{2}$ Center for Industrial Ecology, School of Forestry and Environmental Studies, Yale University, 06511 \\ New Haven, Connecticut, United States \\ ${ }^{3}$ Leiden University, Institute of Environmental Sciences (CML), Einsteinweg 2 (Bio-Science park), 2333 \\ CC Leiden, The Netherlands
}

*Corresponding author: David Font Vivanco; e-mail: d.vivanco@ucl.ac.uk, dfontv@gmail.com; Tel.: +44 02031087387

\begin{abstract}
Resource scarcity poses an increasing threat to the supply security of modern economies. Some grand challenges ahead are the limits to agricultural expansion and the geologic scarcity of metals. To better understand the drivers behind land and metal depletion, footprint-type indicators are gaining importance. Such indicators, however, fail to differentiate between vastly different degrees of resource availability across regions. Using crop suitability areas and metal reserve base data, we calculate scarcity-weighted land and metal footprints for the major economies with the EXIOBASE global multi-regional input-output model. Scarcity-weighting causes a significant reordering of the global rankings of countries for both land and metal footprints. Land scarcity focuses mostly on cereals ( $\sim 54 \%$ from the total agricultural land used) and oil crops ( $\sim 15 \%)$, the former being notably affected by water scarcity issues in Asia and the Middle East. Metal scarcity focuses on copper ores ( 69\%) and iron ( $11 \%)$, the former being a globally scarce metal impacting multiple economies. The large impact of scarcity-weighting suggests that, while non-weighted resource footprints are a valid proxy of resource use, these are not always aligned with further implications of resource depletion and supply security. In this sense, scarcity-weighting can offer an initial overview of those countries where analyses at finer scales may be more valuable. Our results also show that international trade is a major driver of land and metal depletion in some developing regions. This highlights the intersection of environmental justice and globalization, as the burden of resource depletion often falls into poorer regions which critically rely on exports.
\end{abstract}

Keywords: Environmental footprints; input-output analysis; resource scarcity; scarcity-weighted indicators; land use; metals. 


\section{INTRODUCTION}

Modern economies depend on the reliable and sustainable access to a variety of natural resources. Key resources include freshwater, primary energy carriers, arable land, minerals, and metals (EC, 2011; Steffen et al., 2015). The supply security of these resources is affected by systemic constraints at multiple levels (Andrews-Speed et al., 2012). A key constraint is the physical availability of resources, the repercussions of which are expected to increase if current economic growth rates are sustained. Grand challenges include deficits in freshwater availability (WRG, 2009), limits to agricultural land expansion (Popp et al., 2017; van Vuuren and Faber, 2009), and geologic scarcity of some base and minor metals (Henckens et al., 2014). In response to such challenges, resource management policies are increasingly favoring footprint-type indicators in order to better understand the economic drivers behind resource depletion (Tukker et al., 2016).

Resource footprints (RFs) describe the resource requirements associated with or 'embodied' in any given final demand, such as the domestic consumption of any given country (Kitzes, 2013; Rees, 1992; Steen-Olsen et al., 2012). The emerging importance of RFs is due to the fact that many developed countries have stabilized or even decreased resource use within their territorial boundaries, while simultaneously increasing imports from other countries, mostly developing and emerging (Giljum et al., 2016; Tukker et al., 2016). Due to the increasing importance of trade and economic specialization, global models, especially multi-regional input-output (MRIO) models, are seen as a sound and consistent way to calculate RFs (Tukker et al., 2016; Tukker and Dietzenbacher, 2013; Wiedmann et al., 2006). However, RFs generally fail to differentiate between vastly different degrees of resource availability across regions (Lenzen et al., 2013). In other words, by merely keeping track of how much and where resources are being used, they ignore whether, and to which degree, these resources are actually scarce.

The inclusion of scarcity issues in footprint calculations is mostly unexplored, with only a handful of studies that have focused on freshwater scarcity. These studies include those from Lenzen and colleagues (2013) on scarcity-weighted global water footprints, Feng and colleagues (2014) on interregional scarce water footprints in China, and Zhang and colleagues (2017) on scarce water footprints from inter-provincial electricity transmission in China. All of these studies find notable variations in the structure of embodied water flows when scarcity is considered, often disfavoring water-stressed regions that rely on trade. Because considerations of scarcity implicitly factors trade-imbalance and resource exploitation issues into RFs, it can have profound implications for improving local and global resource management practices, as well as provide the clarity necessary for increased social development and environmental justice (Hossay, 2006). Due to the lack of similar exercises for land and metal, however, a similar hypothesis for these resources cannot be resolved.

Although not considering scarcity, the literature provides various examples of land and metal footprints. Land footprints have been calculated for the EU27 member states (Steen-Olsen et al., 2012), world regions (Tukker et al., 2014; Weinzettel et al., 2013) and global household consumption (Ivanova et al., 2016). Metal footprints have been calculated globally for iron and bauxite (Wiedmann et al., 2015), and for metals in general (Bulavskayaa et al., 2016; Giljum et al., 2016). Some of these studies include a form of weighting; the land footprints in Steen-Olsen et al. and Weinzettel et al. are weighted by the bioproductivity of the land, and the metal footprint actually measures the total amount of ore mined and hence represents metal use normalized by the richness of the ore. Not surprisingly, these studies find the biggest economies, such as the United States and China, to lead both land and metal footprints in absolute terms. 
The main research objectives of this paper are (1) to develop a method to calculate global land and metal scarcity-weighted footprints by country/region, (2) to compare the results of this method with their non-weighted equivalents in order to improve the understanding on the economic drivers behind land and metal depletion worldwide, and (3) to assess potential implications for resource management and sustainable development policies.

\section{METHODS}

This section presents the methods and data sources to calculate scarcity-weighted land and metal footprints. A summary of all data sources and related variables is presented in Table 1. To calculate land and metal footprints, we use the MRIO database EXIOBASE 3.3 for the year 2007, which has a resolution of 163 industries and 49 regions ( 44 of the largest world economies and 5 rest-of-continent regions) (Wood et al., 2014). Further details can be found in a number of technical reports (Exiobase, 2017; Koning et al., 2011), and a comparative discussion with other MRIO databases can be found in Moran and Wood (2014), Tukker et al. (2016) and Giljum et al. (2016). According to EXIOBASE 3.3, land is represented by nine different croplands: rice, wheat, 'other cereals', vegetables, fruits and nuts, oil crops, sugar crops, fibers, fodder crops, and 'other crops'. The cropland categories are based on FAOSTAT and the 'other' categories aggregate other FAO crops that are not individually represented. Also according to EXIOBASE 3.3, metal requirements correspond to used extraction of twelve different metal ore types: bauxite and aluminum, copper, gold, iron, lead, nickel, other non-ferrous metals, platinum-group metals, silver, tin, uranium and thorium, and zinc.

Footprints associated with any given final demand were calculated using the standard demand-pull Leontief model (Miller and Blair, 2009):

$$
\text { footprint }_{r}=s_{r} L y=s_{r}(I-A)^{-1} y
$$

Where subscript $r$ indicates a given resource (land or metal type), $s$ is an $n \times 1$ vector of direct resource requirements (s) per unit of economic output, being $n$ the number of industries, $A$ is an $n \times n$ matrix of technical coefficients indicating the inter-industry inputs required to supply one unit of output, $l$ is an $n \times n$ identity matrix, $y$ is a given $1 \times n$ final demand vector, and $L$ is the Leontief inverse containing the multipliers for the direct plus indirect inter-industry inputs required to satisfy one unit of $y$.

In order to incorporate scarcity into our footprint calculations, we apply the approach developed by Lenzen et al. (2013) for virtual water. First, we calculate resource exploitation indices (REls) for each country $i$ by dividing actual resources required (RR) by total resources available (RA):

$$
R E I_{i}=\frac{R R_{i}}{R A_{i}}
$$

Actual resource requirement by country/region in physical units $\left(\mathrm{km}^{2}\right.$ and $\mathrm{kt}$ for each land and metal use type, respectively) is calculated using direct resource requirement (s) data from EXIOBASE 3.3 in order to keep consistency. Resource availability by country/region has been compiled using various data sources as described following. For land, crop suitability areas (CSA) indicating the area in $\mathrm{km}^{2}$ 
suitable to produce a certain crop specie per country have been obtained from the Global Agroecological Zones (GAEZ) 3.0 model (Fischer et al., 2012). Concretely, CSA have been calculated under the following assumptions: all suitability levels, rain-fed water supply, intermediate input level (improved management assumption), without $\mathrm{CO}_{2}$ fertilization, and under current climate conditions. Country-level CSA data have been aggregated to EXIOBASE countries and rest-of-continent regions following the concordances provided in supplementary material S1. Because the GAEZ model is represented by specific crop species, proxies have been assigned when necessary to each cropland type according to the highest global production volume (FAO, 2017) to minimize uncertainty: rice (proxy: wetland rice [Oryza sativa]), wheat, other cereals and other crops (wheat [Triticum spp.]), vegetables, fruits and nuts (tomato [Lycopersicon lycopersicum]), oil crops (sunflower [Helianthus annuus]), sugar crops (sugarcane [Saccharum spp.]), fibers (cotton [Gossypium hirsutum]), and fodder crops (alfalfa [Medicago sativa]). For metals, we use reserve base values by country in kt for the year 2007 reported by the US Geological Service (USGS 2008), except uranium, which is based on OECD and IAEA data (OECD/IAEA 2008). From the USGS data, we use reserve base rather than reserves, because reserves are generally defined in economic terms (extractable metal at current prices) rather than total technically extractable reserves, the latter being more relevant to a scarcity index. The OECD data reports recoverable uranium resources at different cost ranges. Following the same logic, we use the data for the highest reported cost range, namely < USD 130/kgU. Using the REls, we weighted the resource requirements of each country to construct a scarcity-weighted direct resource requirement vectors $\left(s_{r}^{*}\right)$. For example, if a given country extracts $100 \mathrm{kt}$ of iron ore out of a total reserve base of $5000 \mathrm{kt}$, each industry's iron ore requirements will be multiplied by 0.02 . The modified resource requirement vector was then used in equation 1 to calculate a scarcity-weighted resource footprint. We therefore refer to scarce land/metal in cases where the initial footprint has been adjusted. By assigning a higher value to scarce resources, this approach gives a first indication of which countries are more vulnerable to resource depletion from domestic consumption, trade, etc. Due to the unavailability of data, this approach does not consider regional differences in resource availability or quality, nor competition for resources (e.g. competition for land between crops).

Table 1. Summary of variables and related data sources.

\begin{tabular}{|c|c|}
\hline $\begin{array}{l}\text { Variable(s) (within brackets, the symbol of the } \\
\text { associated variable) }\end{array}$ & Data source(s) \\
\hline $\begin{array}{l}\text { Direct resource requirements ( } s \text { and } R R \text { ) for land } \\
\text { use and metal ore use extraction, technical } \\
\text { coefficient matrix }(A) \text {, and final demand vector } \\
(y) \text { by industry sector. }\end{array}$ & EXIOBASE 3.3 (Wood et al., 2014) \\
\hline Crop suitability areas ( $\left.\mathrm{RA}_{\text {land }}\right)$ by country. & $\begin{array}{l}\text { Global Agro-ecological Zones (GAEZ) } 3.0 \text { model } \\
\text { (Fischer et al., 2012) }\end{array}$ \\
\hline Crop production volumes by country ( $\left.R A_{\text {land }}\right)$. & $\begin{array}{l}\text { Food and Agriculture Organization crop } \\
\text { production data (FAO, 2017) }\end{array}$ \\
\hline Metal reserve base by country $\left(\mathrm{RA}_{\text {metal }}\right)$ & US Geological Service (USGS 2008) \\
\hline Uranium reserve base by country ( $\left.R A_{\text {metal }}\right)$ & OECD and IAEA (OECD/IAEA 2008) \\
\hline
\end{tabular}

\section{RESULTS AND DISCUSSION}

\subsection{Scarcity-weighted land footprints}


Considering land scarcity caused significant shifts in the global ranking of countries for direct land use, land footprint (land embodied in domestic consumption) as well as land embodied in net trade (land embodied in exports minus land embodied in imports), as shown in Figure 1. Starting with direct land use, some countries and regions, such as India and the Middle East, were penalized in the global ranking due to a more intensive use of some of their land resources (represented by higher exploitation indices [Els]). This caused these countries to gain positions in the scarcity-weighted ranking (in decreasing order) with respect to the non-weighted one. India moved from the third to the first position, and the disaggregated results show that scarce land was largely associated with rice crops (see supporting information S1). This is consistent with concerns over the impact of water scarcity and the consequent limited expansion possibilities of rice crops in some rice-growing areas in Asia (Tuong and Bouman, 2003). For the Middle East, the difference is more notable as the region moved up ten positions to the third position. In this case, almost half of the scarce land corresponds to wheat crops, a water-intensive crop which is similarly affected by water scarcity issues in countries such as Saudi Arabia (Allan, 1997). High land scarcity implies more limited expansion possibilities for key crops without major land conversions and/or additional biodiversity impacts (Foley et al., 2005), as well as an increased reliance on technical intensification to meet future food demand increases. Globally, direct land use scarcity focused mostly on cereals other than rice and wheat ( 34\%), wheat ( 20\%), and oil crops ( 15\%).

Global land footprints were also affected by scarcity considerations, yet to a lesser degree. For instance, India and Indonesia gained a few positions in the global ranking, largely due to scarce land embedded in domestic consumption and exports of water-intensive rice and cereal crops, respectively. On the other hand, countries such as Russia and Brazil lost positions by benefitting from relatively lower Els along the supply chains of their consumption. For Russia, lower Els are mostly associated with domestic consumption of wheat and other cereals, which present high expansion possibilities thanks to extensive unused land resources and large yield gaps (Schierhorn et al., 2014). For Brazil, it is largely associated with domestic consumption of vegetables, fruits, nuts, and sugar crops, and it is consistent with estimates that puts the country as the one with the greatest potential for further agricultural expansion (Alexandratos and Bruinsma, 2012). Regarding net trade, the most noticeable differences relate to Indonesia and the Middle East region, which significantly increase their roles as net exporters. For Indonesia, this is largely driven by large exports of oil and other crops, which have limited expansion possibilities without further deforestation (ICCT, 2016). For the Middle East, it is mostly driven by exports of vegetables, fruits, nuts and wheat crops, the expansion possibilities of which are limited by water scarcity in the region (Allan, 1997). 

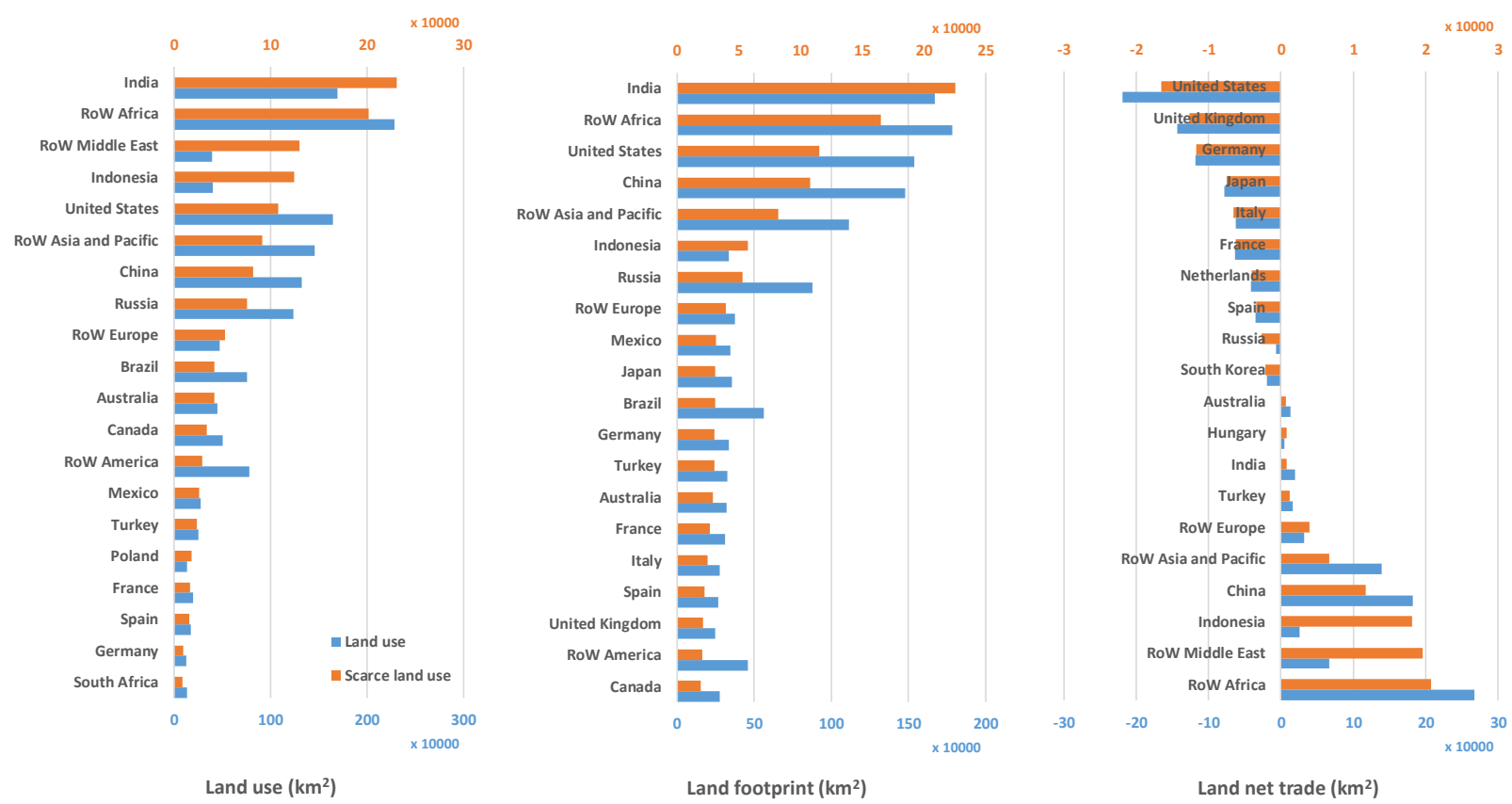

Figure 1. Direct land use (left), land footprint (center) and land embodied in net trade (right) according to scarcity-weighted and non-weighted land use for the year 2007. Net trade corresponds to exports minus imports. For direct land use and land footprint, only the top 20 in descending order are shown. For land embodied in net trade, only the top 10 and bottom 10 in ascending order are shown. The complete results can be found in supporting information $\mathrm{S} 1$.

\subsection{Scarcity-weighted metal footprints}

Considering metal scarcity similarly caused significant changes in the relative positioning of countries for direct metal extraction, metal footprint and metal net trade. The results are shown in Figure 2 . Starting with direct metal extraction, some countries and regions, such as the U.S. and the Asia-Pacific region, were significantly penalized for their more intensive metal extraction rates. For the U.S., metal scarcity focused mostly on copper ores, whereas the Asia-Pacific region was impacted on both copper and iron ores. In fact, copper led global extraction of scarce metal with $69 \%$ from the total scarce metal extracted. Copper scarcity is a known issue that is expected to notably impact economies worldwide (Harmsen et al., 2013). Conversely, countries like Brazil, India, and China were favored in the global ranking as these had less intensive extraction rates. Aside from copper, other relevant scarce metals extracted globally were iron ( $11 \%$ from the total direct scarce metal extraction), nickel ( 8\%), and zinc ( 7\%).

Global metal footprints were also notably affected by the metal scarcity weightings. For instance, the regions of RoW America and RoW Asia-Pacific gained positions in the global ranking because of their consumption of copper, a scarce metal extracted in countries with relatively higher Els, including own extraction but also imports from the U.S. and China. Conversely, countries like Indonesia and Brazil lost positions by benefiting from relatively lower Els along the supply chains associated with their final demand. Regarding scarce metal embodied in net trade, an interesting finding is that its sign changed for some countries and regions with respect to the non-weighted calculations. For example, the AsiaPacific region went from being a net exporter to being a net importer of scarce metal. An important reason for this is the imports of copper ores from the U.S. and other countries with high Els. In other 
cases, such as in the RoW America region, exports of scarce metals, especially copper and zinc ores, were accentuated due to its high reliance on trade.
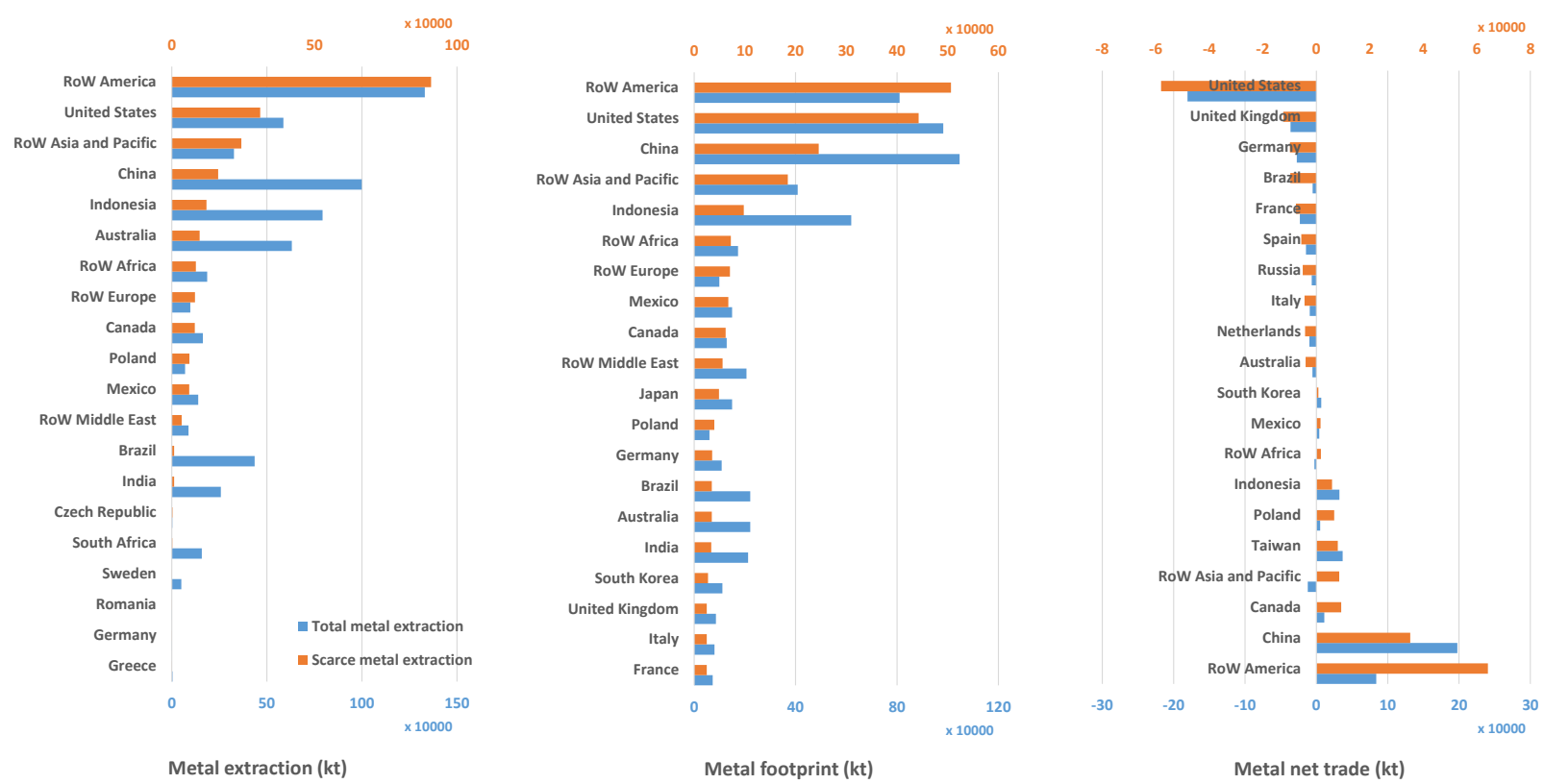

Figure 2. Direct metal extraction (left), metal footprint (center) and metal embodied in net trade (right) according to scarcity-weighted and non-weighted metal extraction for the year 2007. Net trade corresponds to exports minus imports. For direct metal extraction and metal footprint, only the top 20 in descending order are shown. For metal embodied in net trade, only the top 10 and bottom 10 in ascending order are shown. The complete results can be found in supporting information S1.

\section{CONCLUSION}

In this research, we apply for the first time the concept of scarcity-weighted footprints to global land use and metal extraction. We find that land scarcity focuses mostly on cereal cropland, whereas metal scarcity focuses mostly on copper ores. Our results also show that land and metal footprints are notably affected by considerations of scarcity. This finding is consistent with similar studies that focused on freshwater consumption. Scarcity causes in some cases a significant reordering of the global rankings of direct use, footprint and net trade, both for land use and metal extraction. For some countries, considering scarcity even reverses the sign of net trade (from net exporters to net importers of scarce land/metals and vice versa). The large impact of scarcity-weighting suggests that, while nonweighted resource footprints are a valid proxy of resource use, these are not always aligned with further implications of resource depletion and supply security. In this sense, scarcity-weighting can offer an initial overview of those countries where analyses at finer scales may be more valuable.

The concept of scarcity-weighted footprints complements previous research on the economic drivers behind global land and metal depletion, especially with regards to the role of international trade. In this sense, our results show that exports are a major driver of land and metal depletion in some developing regions. This highlights the intersection of environmental justice and globalization, as the burden of resource depletion often falls into poorer regions which critically rely on exports, a vicious 
circle that jeopardizes their future development (Rees and Westra, 2003; Ross, 2011). Land, metal and freshwater resources are all vulnerable to supply security issues in some regions due to their limited availability. In this context, we recommend both domestic resource management and sustainable development policies to include scarcity considerations, such as the proposed scarcity-weighted method, in domestic use and footprint calculations. Such considerations can help countries in managing key resources from the viewpoint of their natural capital endowments, for instance via resource quotas (Daly, 1977). Developed nations can also benefit from this information by shifting trade patterns to comply with sustainable development goals (Griggs et al., 2013) and minimise supply risks stemming from climate change, trade restrictions, conflict, etc. Furthermore, considering the differences in economic development, comparative advantages in terms of production technologies, and natural endowments, international trade can serve to find optimal solutions in terms of economic development, environmental justice, and the use of scarce natural resources (Steen-Olsen et al., 2012).

While our approach to incorporate scarcity into footprint calculations is straightforward and transparent, our results suffer from inherent limitations that could be tackled in future research. First, previous research has demonstrated that low resolution analyses, for example at the country level, may result in biased exploitation indices and may overlook scarcity issues at the local level (Zhang et al., 2017). Tackling this issue would involve either building and trade-linking sub-national input-output tables (Faturay et al., 2017; Lenzen et al., 2014; Su et al., 2010) and/or mapping location-specific production activity and environmental impacts (Moran and Keiichiro, 2016; Moran et al., 2016; Wang and Zimmerman, 2016). Second, the indicators used to reflect the physical availability of land and metal ores could be improved. For instance, by considering competing uses for land through prices or productivity. Third, metal scarcity was calculated using self-reported data from countries and mining companies which, in the case of some developing countries, might not be entirely accurate. To improve this aspect, future research must focus on compiling empirical data on metal extraction and use. Lastly, we also note that, for metals, the main threat to supply security is often not the geological scarcity, but rather geopolitically-motivated supply restrictions, as exemplified in the rare earths crisis of 2010 (Sprecher et al., 2017). In this sense, our conclusions on supply security from the viewpoint of scarcity alone must be contextualized according to geopolitical and market conditions. Despite its limitations, this research shows that, for some resources and regions, scarcity considerations are not only pertinent, but critical to understand the drivers behind resource depletion and to design better resource management practices.

\section{REFERENCES}

Alexandratos, N., Bruinsma, J., 2012. World Agriculture Towards 2030/2050: The 2012 Revision. ESA Working Paper No. 12-03, in: FAO (Ed.).

Allan, J.A., 1997. 'Virtual water': a long term solution for water short Middle Eastern economies? School of Oriental and African Studies, University of London, London.

Andrews-Speed, P., Bleischwitz, R., Boersma, T., Johnson, C., Kemp, G., VanDeveer, S.D., 2012. The global resource nexus : the struggles for land, energy, food, water, and minerals. Transatlantic Acad., Washington, DC.

Bulavskayaa, T., Hua, J., Moghayera, S., Reynèsa, F., 2016. EXIOMOD 2.0: EXtended Input-Output MODel. A full description and applications, TNO Working Paper Series [http://resolver.tudelft.nl/uuid:3c658012-966f-4e7a-8cfe-d92f258e109b]. 
Daly, H., 1977. The Steady-state Economy. The Sustainable Society: Implications for Limited Growth. Praeger, New York and London.

EC, 2011. Roadmap to a resource efficient Europe, COM (2011) 571. European Commission.

Exiobase, 2017. EXIOBASE2 Documentation

[http://exiobase.eu/index.php/publications/documentation/77-exiobase2-documentation].

FAO, 2017. FAOSTAT - Crops [http://www.fao.org/faostat/en/\#data/QC].

Faturay, F., Lenzen, M., Nugraha, K., 2017. A new sub-national multi-region input-output database for Indonesia. Economic Systems Research 29(2), 234-251.

Feng, K., Hubacek, K., Pfister, S., Yu, Y., Sun, L., 2014. Virtual Scarce Water in China. Environmental Science \& Technology 48, 7704-7713.

Fischer, G., Nachtergaele, F.O., Prieler, S., Teixeira, E., Tóth, G., Van Velthuizen, H., Verelst, L., Wiberg, D., 2012. Global Agro-ecological Zones (GAEZ v3. 0) - Model Documentation, in: IIASA/FAO (Ed.).

Foley, J.A., DeFries, R., Asner, G.P., Barford, C., Bonan, G., Carpenter, S.R., Chapin, F.S., Coe, M.T., Daily, G.C., Gibbs, H.K., Helkowski, J.H., Holloway, T., Howard, E.A., Kucharik, C.J., Monfreda, C., Patz, J.A., Prentice, I.C., Ramankutty, N., Snyder, P.K., 2005. Global Consequences of Land Use. Science 309, 570-574.

Giljum, S., Wieland, H., Lutter, S., Bruckner, M., Wood, R., Tukker, A., Stadler, K., 2016. Identifying priority areas for European resource policies: a MRIO-based material footprint assessment. Journal of Economic Structures 5(17), 1-24.

Griggs, D., Stafford-Smith, M., Gaffney, O., Rockstrom, J., Ohman, M.C., Shyamsundar, P., Steffen, W., Glaser, G., Kanie, N., Noble, I., 2013. Policy: Sustainable development goals for people and planet. Nature 495, 305-307.

Harmsen, J.H.M., Roes, A.L., Patel, M.K., 2013. The impact of copper scarcity on the efficiency of 2050 global renewable energy scenarios. Energy 50, 62-73.

Henckens, M.L.C.M., Driessen, P.P.J., Worrell, E., 2014. Metal scarcity and sustainability, analyzing the necessity to reduce the extraction of scarce metals. Resources, Conservation and Recycling 93, 18.

Hossay, P., 2006. Unsustainable: a primer for global environmental and social justice. Zed Books, London and New York.

ICCT, 2016. Ecological impacts of palm oil expansion in Indonesia, International Council on Clean Transportation (Ed.) [http://www.theicct.org/sites/default/files/publications/Indonesia-palm-oilexpansion_ICCT_july2016.pdf].

Ivanova, D., Stadler, K., Steen-Olsen, K., Wood, R., Vita, G., Tukker, A., Hertwich, E.G., 2016.

Environmental Impact Assessment of Household Consumption. Journal of Industrial Ecology 20, 526536.

Kitzes, J., 2013. An Introduction to Environmentally-Extended Input-Output Analysis. Resources 2(4), 489-503.

Koning, A., Heijungs, R., Tukker, A., 2011. Database filled with all data and EXIOBASE database management system including agreed scripts operational. Deliverable DIII.4.b-5, Report of the EXIOPOL project [http://www.exiobase.eu/index.php/publications/documentation]. 
Lenzen, M., Geschke, A., Wiedmann, T., Lane, J., Anderson, N., Baynes, T., Boland, J., Daniels, P., Dey, C., Fry, J., Hadjikakou, M., Kenway, S., Malik, A., Moran, D., Murray, J., Nettleton, S., Poruschi, L., Reynolds, C., Rowley, H., Ugon, J., Webb, D., West, J., 2014. Compiling and using input-output frameworks through collaborative virtual laboratories. Science of The Total Environment 485-486, 241-251.

Lenzen, M., Moran, D., Bhaduri, A., Kanemoto, K., Bekchanov, M., Geschke, A., Foran, B., 2013. International trade of scarce water. Ecological Economics 94, 78-85.

Miller, R.E., Blair, P.D., 2009. Input-output analysis: foundations and extensions. Cambridge University Press, Cambridge, United Kingdom.

Moran, D., Keiichiro, K., 2016. Tracing global supply chains to air pollution hotspots. Environmental Research Letters 11(9), 1-7.

Moran, D., Petersone, M., Verones, F., 2016. On the suitability of input-output analysis for calculating product-specific biodiversity footprints. Ecological Indicators 60, 192-201.

Moran, D., Wood, R., 2014. Convergence between the Eora, Wiod, Exiobase, and OpenEU's consumption-based carbon accounts. Economic Systems Research 26, 245-261.

OECD/IAEA, 2008. Uranium 2007: Resources, Productionand Demand. Organisation for Economic Cooperation and Development Nuclear Energy Agency and the International Atomic Energy Agency [https://www.oecd-nea.org/ndd/pubs/2008/6345-uranium-2007.pdf].

Popp, A., Calvin, K., Fujimori, S., Havlik, P., Humpenöder, F., Stehfest, E., Bodirsky, B.L., Dietrich, J.P., Doelmann, J.C., Gusti, M., Hasegawa, T., Kyle, P., Obersteiner, M., Tabeau, A., Takahashi, K., Valin, H., Waldhoff, S., Weindl, I., Wise, M., Kriegler, E., Lotze-Campen, H., Fricko, O., Riahi, K., Vuuren, D.P.v., 2017. Land-use futures in the shared socio-economic pathways. Global Environmental Change 42, 331-345.

Rees, W.E., 1992. Ecological footprints and appropriated carrying capacity: what urban economics leaves out. Environment and Urbanization 4, 121-130.

Rees, W.E., Westra, L., 2003. When consumption does violence: can there be sustainability and environmental justice in a resource-limited world. In: Agyeman, J., Bullard, R. D. \& Evans, B. (Ed.) Just sustainabilities: Development in an unequal world, 99-124.

Ross, M.L., 2011. The Political Economy of the Resource Curse. World Politics 51, 297-322.

Schierhorn, F., Müller, D., Prishchepov, A.V., Faramarzi, M., Balmann, A., 2014. The potential of Russia to increase its wheat production through cropland expansion and intensification. Global Food Security 3, 133-141.

Sprecher, B., Daigo, I., Spekkink, W., Vos, M., Kleijn, R., Murakami, S., Kramer, G.J., 2017. Novel Indicators for the Quantification of Resilience in Critical Material Supply Chains, with a 2010 Rare Earth Crisis Case Study. Environmental Science \& Technology 51, 3860-3870.

Steen-Olsen, K., Weinzettel, J., Cranston, G., Ercin, A.E., Hertwich, E.G., 2012. Carbon, Land, and Water Footprint Accounts for the European Union: Consumption, Production, and Displacements through International Trade. Environmental Science \& Technology 46, 10883-10891.

Steffen, W., Richardson, K., Rockström, J., Cornell, S.E., Fetzer, I., Bennett, E.M., Biggs, R., Carpenter, S.R., de Vries, W., de Wit, C.A., Folke, C., Gerten, D., Heinke, J., Mace, G.M., Persson, L.M., Ramanathan, V., Reyers, B., Sörlin, S., 2015. Planetary boundaries: Guiding human development on a changing planet. Science 347, 1-10. 
Su, B., Huang, H.C., Ang, B.W., Zhou, P., 2010. Input-output analysis of CO2 emissions embodied in trade: The effects of sector aggregation. Energy Economics 32, 166-175.

Tukker, A., Bulavskaya, T., Giljum, S., de Koning, A., Lutter, S., Simas, M., Stadler, K., Wood, R., 2014. The Global Resource Footprint of Nations-Carbon, Water, Land and Materials Embodied in Trade and Final Consumption Calculated with Exiobase 2.1. Leiden/Delft/Vienna/Trondheim.

Tukker, A., Bulavskaya, T., Giljum, S., de Koning, A., Lutter, S., Simas, M., Stadler, K., Wood, R., 2016. Environmental and resource footprints in a global context: Europe's structural deficit in resource endowments. Global Environmental Change 40, 171-181.

Tukker, A., Dietzenbacher, E., 2013. Global multiregional input-output frameworks: an introduction and outlook. Economic Systems Research 25, 1-19.

Tuong, T., Bouman, B., 2003. Rice production in water-scarce environments, in: Kijne, J., Barker, R., Molden, D. (Eds.), Water productivity in agriculture: Limits and opportunities for improvement, pp. $13-42$.

van Vuuren, D.P., Faber, A., 2009. Growing within limits : a report to the Global Assembly 2009 of the Club of Rome. Netherlands Environmental Assessment Agency (PBL), Bilthoven.

Wang, R., Zimmerman, J., 2016. Hybrid Analysis of Blue Water Consumption and Water Scarcity Implications at the Global, National, and Basin Levels in an Increasingly Globalized World.

Environmental Science \& Technology 50, 5143-5153.

Weinzettel, J., Hertwich, E.G., Peters, G.P., Steen-Olsen, K., Galli, A., 2013. Affluence drives the global displacement of land use. Global Environmental Change 23, 433-438.

Wiedmann, T., Minx, J., Barrett, J., Wackernagel, M., 2006. Allocating ecological footprints to final consumption categories with input-output analysis. Ecological Economics 56, 28-48.

Wiedmann, T.O., Schandl, H., Moran, D., 2015. The footprint of using metals: new metrics of consumption and productivity. Environmental Economics and Policy Studies 17, 369-388.

Wood, R., Stadler, K., Bulavskaya, T., Lutter, S., Giljum, S., de Koning, A., Kuenen, J., Schütz, H., Acosta-Fernández, J., Usubiaga, A., Simas, M., Ivanova, O., Weinzettel, J., Schmidt, J., Merciai, S., Tukker, A., 2014. Global Sustainability Accounting-Developing EXIOBASE for Multi-Regional Footprint Analysis. Sustainability 7, 138-163.

WRG, 2009. Charting Our Water Future: Economic frameworks to inform decision-making, Water Research Group, McKinsey \& Company, New York.

Zhang, C., Zhong, L., Liang, S., Sanders, K.T., Wang, J., Xu, M., 2017. Virtual scarce water embodied in inter-provincial electricity transmission in China. Applied Energy 187, 438-448. 